\title{
Compressibility Behaviour of Borneo Tropical Peat Stabilized with Lime-Sand Column
}

\author{
Jodin Makinda", Lillian Gungat", N.S.V Kameswara Rao", Solomon Sulis* \\ ${ }^{\#}$ Civil Engineering Program, Faculty of Engineering, Universiti Malaysia Sabah, 88400 Kota Kinabalu, Sabah, Malaysia \\ E-mail: jodin@ums.edu.my, lillian@ums.edu.my,nsv@ums.edu.my
}

*Perunding BSK Sdn Bhd, Jalan Damai, 88300, Kota Kinabalu, Sabah, Malaysia

E-mail:solomon_sulis@yahoo.com

\begin{abstract}
Construction on peat soils can have two alternatives, either to excavate and replace the weak soil or to improve the soil strength using soil stabilizers such as lime and other ground improvement method such as soil column. This paper studies the properties of Borneo tropical peat soil and the effect of lime-sand-column to the value of the void ratio, the coefficient of consolidation, volume compressibility, and compressibility of the stabilized soil. After the engineering properties of the peat were determined, consolidation test was performed to observe the effect of the lime-sand column for 1 and 3 curing days with lime percentages of 3 and $6 \%$ lime. Tests were then repeated using a different number of lime-sand column. It was observed that the compressibility of the peat soil was reduced using a longer period of curing, a higher percentage of lime, and a higher number of sand columns.
\end{abstract}

Keywords — soil stabilisation; Borneo peat; lime column; sand column; compressibility

\section{INTRODUCTION}

Depleting land resources had led to the utilization of existing scarcely available land and soil investigation is a must in order to get information regarding properties such as strength, bearing capacity and compressibility. There are two common alternatives in dealing with weaker soils such as peat; excavation or replacement with stronger or stabilised soil. The choice depends on several construction factors such as overall cost, lifespan design or time for completion. However, large construction projects tend to avoid the costly soil replacement, and therefore soil stabilization is warranted.

Approximately $60 \%$ of the currently known tropical peatlands occur in Southeast Asia, mostly in Indonesia, Malaysia, Brunei, and Thailand, and to a lesser extent in the Philippines [1] and they have greatly impacted human development. In Malaysia for example, the 9th Malaysia Plan unveiled the economic plan to include the construction for RM 27 billion Pan Borneo Highway, a 2083 kilometers road network connecting two states, Sabah and Sarawak along several low-land peat areas. As the preliminary study indicates, the implementation of the project would need the expertise on soft soil development to carry out the project so as to avoid cost overruns [2]. Therefore, as highlighted by the Work Minister, contractors would need to work with research institutes and experts to find a better solution for problematic soil areas along the road network.

This is an ever-present dilemma faced by construction on Malaysia tropical soils. They generally have the low shear strength and high compressibility. As such, problems like large settlements, soil subsidence and lateral movement that cause damage to infrastructure and foundation failure are common [3]. In high areas, over 400 landslides have been reported in the last two decades where more than 30 were major landslides, involving both cut and natural slopes with a total loss of more than 200 lives and billions of Ringgit in damage to property. These hazards are frequent occurrence due to Malaysia's unfavorable geological and geographical setting [4].

Peat soil is made of representative material from soft soil and known for containing more than $70 \%$ organic content. Generally, peat soil is composed of fibrous organic matters such as partly decomposed plants like stems and leaves. The high organic residues of plants in peat are incompletely decomposed due to lack of oxygen. Peat soils are formed by disintegration of organic matters and plant and characterized by very high void ratio and water contents. Hence, it can be said that the geotechnical properties of peat soil are unique as compared to that of inorganic soils such as sandy soils and clay which contains mostly soil particles. 
Peat is well known for its poor properties such as; easily deform and fail under a light surcharge load, low shear strength, high compressibility, high water content [5], low bearing capacity, influenced by the existence of subsurface woody debris [6] and high amount of organic and fiber content soil with low humification [7]. Locally, Borneo tropical peat is also identified as spongy, unstable, waterlogged, anaerobic beds of up to $20 \mathrm{~m}$ deep with low $\mathrm{pH}$ between 2.9-4 and contains low nutrients [8].

Several chemical stabilisation materials, such as cement, lime, fly ash, blast furnace slag, calcium sulfate, and gypsum has been used to improve and stabilized weak peat and residual soils. Ahnberg [9] found that for most type of soils, lime is found to be an economical way of soil stabilization and modification through cation exchange capacity. In addition, mechanical improvement is also common, such as the use of geosynthetic reinforcement to improve its bearing capacity [10] and non-woven geosynthetic clay liner (GCL) to improve the interface shear strength properties [11].

The previous study on the compressibility of peat soil upon cement stabilization found that there is a substantial decrease in the compression for stabilized soil [12]. The result shows that with the increasing duration of curing in water, the yield stress of the peat soil increase as well. This trend of strength gaining is in accordance with the progressive increase in strength with the vertical strain of the stabilized soils in unconfined compression tests. The ratio of coefficient of secondary compression to compressibility index of the stabilized peat was discovered to be higher at 28 days of curing time as compared to that of 90 and 240 days. This demonstrated the possible effects of curing in the stabilisation of peat soil.

Several studies have been conducted in investigating the improvement of weak soils using lime as the admixture, but limited available data on Borneo tropical peat soil stabilized with the lime-sand column. Hence, this study aims to investigate the effect of the lime-sand column to its compressibility behavior.

\section{MATERIAL AND METHOD}

\section{A. Material}

Samples of peat soil collected from a swamp forest near Papar about $40 \mathrm{~km}$ from Kota Kinabalu, Sabah. Trial pits were excavated up to a depth of $0.5 \mathrm{~m}$ below the ground for the purpose of soil sampling. The laboratory tests consisted of soil classification, characterizations, compaction, and compressibility were conducted. The lime was supplied by UMS Civil Engineering Laboratory.

\section{B. Method}

The soil was classified using the Von Post scale of humification. Properties such as $\mathrm{pH}$, specific gravity, organic content, moisture content, maximum dry density and optimum water content from the Proctor compaction test were obtained according to BS 1377-1990. Meanwhile, the Initial Consumption of Lime (ICL) test to determine the suitable lime percentage to be added was conducted according to BS1924-1990. Finally, the compressibility of soil was determined using consolidation method according to BS1377-1990.

\section{Specimen Variables}

After soil characterization and compaction test, thirteen remoulded specimens of peat soil were prepared and tested for compressibility behaviour including the control sample. The samples were treated with 3 and $6 \%$ of lime-sand mixes inserted into a trimmed hole in the middle to form one or two columns and cured for 1 or 3 days under the optimum moisture content. The sample combinations and detail descriptions are shown in Table 1 below.

TABLE I

SPECIMEN DESCRIPTIONS

\begin{tabular}{|c|c|c|c|}
\hline Sample & $\begin{array}{c}\text { Lime in Sand } \\
\text { Column, \% }\end{array}$ & $\begin{array}{c}\text { No of } \\
\text { Column }\end{array}$ & Curing, Day(s) \\
\hline 0L0D0S & 0 & 0 & 0 \\
\hline 3L1D0S & 3 & 0 & 1 \\
\hline 3L3D0S & 3 & 0 & 3 \\
\hline 6L1D0S & 6 & 0 & 1 \\
\hline 6L3D0S & 6 & 0 & 3 \\
\hline 3L1D1S & 3 & 1 & 1 \\
\hline 3L3D1S & 3 & 1 & 3 \\
\hline 6L1D1S & 6 & 1 & 1 \\
\hline 6L3D1S & 6 & 1 & 3 \\
\hline 3L1D2S & 3 & 2 & 1 \\
\hline 3L3D2S & 3 & 2 & 3 \\
\hline 6L1D2S & 6 & 2 & 1 \\
\hline 6L3D2S & 6 & 2 & 3 \\
\hline
\end{tabular}

After the specified curing period, the specimens were then subjected to five loading and two unloading pressures.

\section{RESULTS AND DISCUSSION}

\section{A. Classification and Engineering Properties of Borneo Tropical Peat Soil}

Table II below shows the properties of the Borneo tropical peat. Classification based on Von Post scale matched those of H6, a common value obtained for peat in Borneo of Sabah region. A similar study in Beaufort a nearby district classifies the Borneo tropical peat soil as H6 and H7 [13].

TABLE II

PROPERTIES OF BORNEO TROPICAL PEAT SOIL

\begin{tabular}{|l|c|}
\hline \multicolumn{1}{|c|}{ Properties } & Parameters \\
\hline Von Post Classification & $\mathrm{H} 6$ \\
\hline $\mathrm{pH}$ & 5.37 \\
\hline Specific Gravity & 1.50 \\
\hline Natural Moisture Content, $\%$ & 646.45 \\
\hline Organic Content, $\%$ & 79.50 \\
\hline Maximum Dry Density, $\mathrm{kg} / \mathrm{m}^{3}$ & 568 \\
\hline Optimum Water Content, $\%$ & 74.0 \\
\hline Initial Consumption of Lime (ICL), $\%$ & 6.0 \\
\hline
\end{tabular}

Through visual observation, the peat soil is found to possess moderately highly decomposed vegetation with a very indistinct plant structure. Upon squeezing, about onethird of the peat escapes between fingers. The residue is very pasty and shows the plant structure more clearly than before squeezing.

In addition, the Borneo peat in this Sabah region was found to have a high natural moisture content of $646.45 \%$. By comparison, the moisture content of peat obtained from 
neighbouring Borneo state of Sarawak is ranging from 360.72 to $473.70 \%$ [14]. Samples collected from a location in other states of Peninsular Malaysia recorded findings of 710.44 [15] and $472 \%$ [16]. The variations of these results attribute to the climate change that is manifested by changes in temperature, precipitation, and rainfall which influences the intensity of soil saturation [13].

The organic content test yields a value of $79.5 \%$, higher than the $70 \%$ minimum requirement for peat proposed by Huat [5] and bear a resemblance to the previous studies in Sarawak and Peninsular Malaysia states. High organic content shows that the peat soil is mainly composed of dead plants and other disintegrated organic matter. The soil is usually classified as organic soil when the organic content is more than $20 \%$, where peat soil falls in this category.

The $\mathrm{pH}$ test yields a value of 5.37, indicating that it is acidic in nature. The sampling area is located nearby agricultural activities where peat burning is common in the dry season. In addition, it was observed that the area is lacking in term of drainage system hence causes the groundwater to be retained and trapped making it more acidic. Another major factor could be the age of soil fibre [11].

The saturation percentage of lime during the ICL test was found to be $6 \%$ and stabilized at $\mathrm{pH}$ of 10.1 . Theoretically, this value is the optimum percentage for the stabilization of peat soil using lime. Hence, this value is adopted along with other values which are 0 (for control sample) and $3 \%$ for comparison purpose.

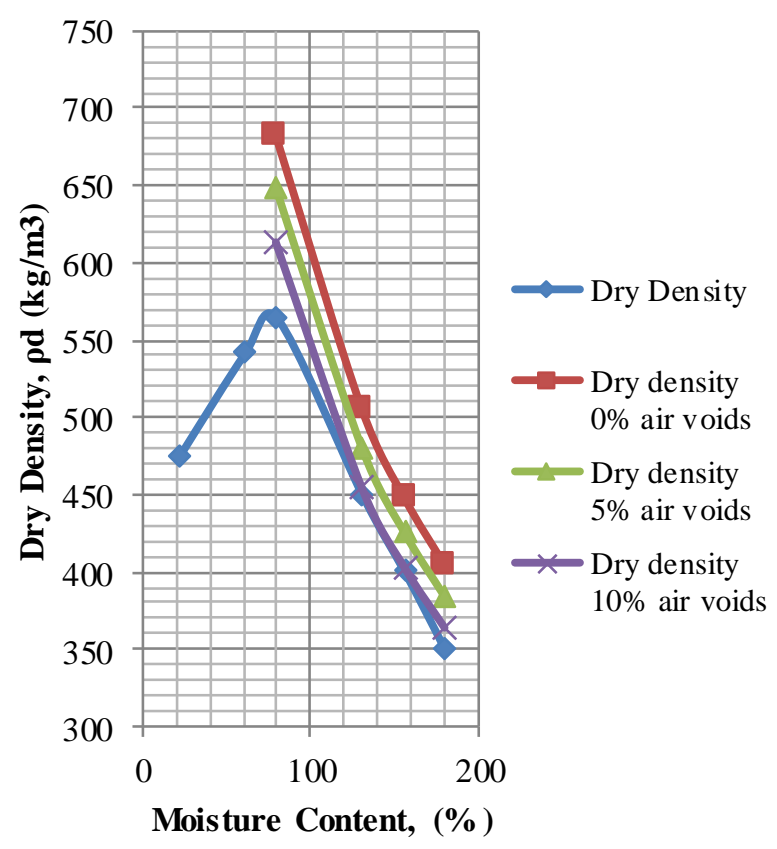

Fig. 1 Compaction curve of Borneo tropical peat soil

The standard proctor compaction test was conducted to determine the maximum dry density (MDD) and optimum moisture content, OMC as shown in Fig. 1. From the figure, the MDD of the peat soil is found to be $568 \mathrm{~kg} / \mathrm{m}^{3}$, and the $\mathrm{OMC}$ is $74 \%$. The reason for the low MDD can be attributed to the low specific gravity of 1.50 and high air void content, as observed in the plotted saturation lines.

\section{B. Compressibility Behaviour of Borneo Tropical Peat Soil}

The void ratio, e-log p curves shown in Fig. 2 were used to evaluate the long-term compression behavior of the soil and also to compare the compression of each soil sample. The control sample possesses the highest initial void ratio, which is 9.656 and upon loading pressures the void ratio decreases and subsequently increases slightly upon unloading pressure. A similar trend was observed among all the peat soil samples.

The high void ratio observed in all samples is due to the high gaseous content of the soil emitted by organic content. Upon loading, the void ratio decreases due to the expulsion of air from the sample. During unloading, the void ratio increases a slightly to the air absorption by peat soil. Lime percentages found to have an effect on the void ratio. Peat treated with $6 \%$ lime has lower void ratio compared to the control and other samples having lower lime percentages. For example, the initial void ratio of peat treated with 6,3 lime and $0 \%$ lime are 9.069, 9.709, 9.908 respectively.

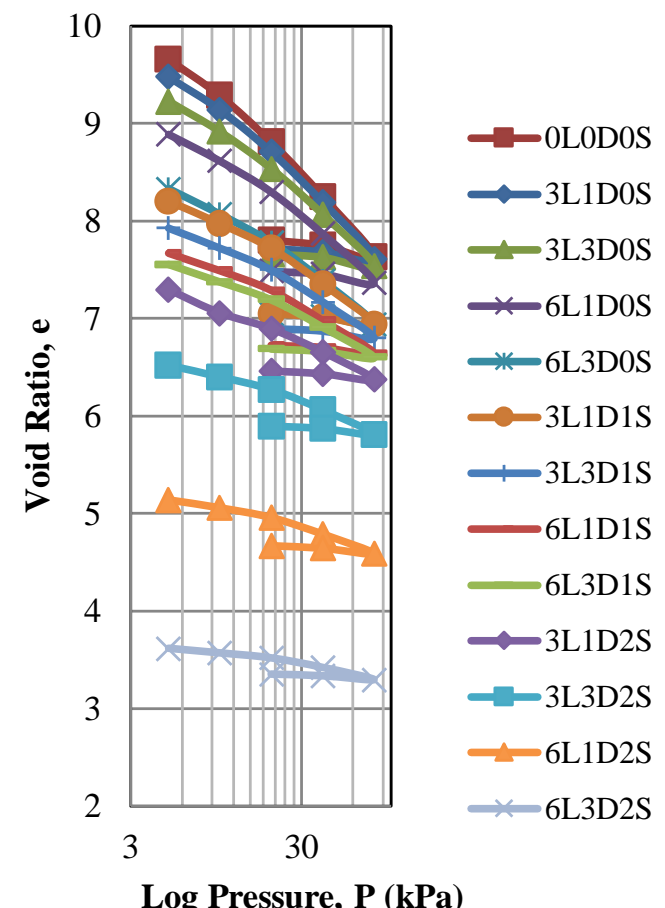

Fig. 2 e-log P graph for Borneo peat soil

By increasing the curing time to 3 days using the same lime percentage, a further reduction was observed. A comparison between control sample, peat treated with $3 \%$ lime cured for one day and peat treated with $3 \%$ lime cured for three days, shows that the initial void ratio is reduced which are 9.908, 9.709 and 9.425 respectively. The introduction of the sand column shows a further reduction in the void ratio of peat soil. The value of void ratio are 9.908 , 8.349 , and 7.296 respectively for the control sample, peat treated with $3 \%$ lime cured for one day and added with one 
sand column, and peat treated with $3 \%$ lime cured for one day and added with the double sand column.

The results are shown in Fig. 3 shows a noticeable reduction in the coefficient of consolidation, $c_{v}$ with the increase of pressure, in agreement with a study on peat soil from Johor state [17]. The untreated sample possessed the highest value of $c_{v}$, that is $0.2 \mathrm{~cm}^{2} / \mathrm{min}$. In terms of lime percentage, the sample treated with 3 and $6 \%$ lime, both cured for 1 day show a $c_{v}$ of 0.195 and $0.180 \mathrm{~cm}^{2} / \mathrm{min}$, indicating a higher percentage of lime reduces the $c_{v}$ of peat soil. Meanwhile, longer curing period can also reduce the $\mathrm{c}_{\mathrm{v}}$ of soil. For example, the samples treated with $6 \%$ lime cured for 1 and 3-day each shows the value of 0.180 and 0.175 $\mathrm{cm}^{2} /$ min respectively.

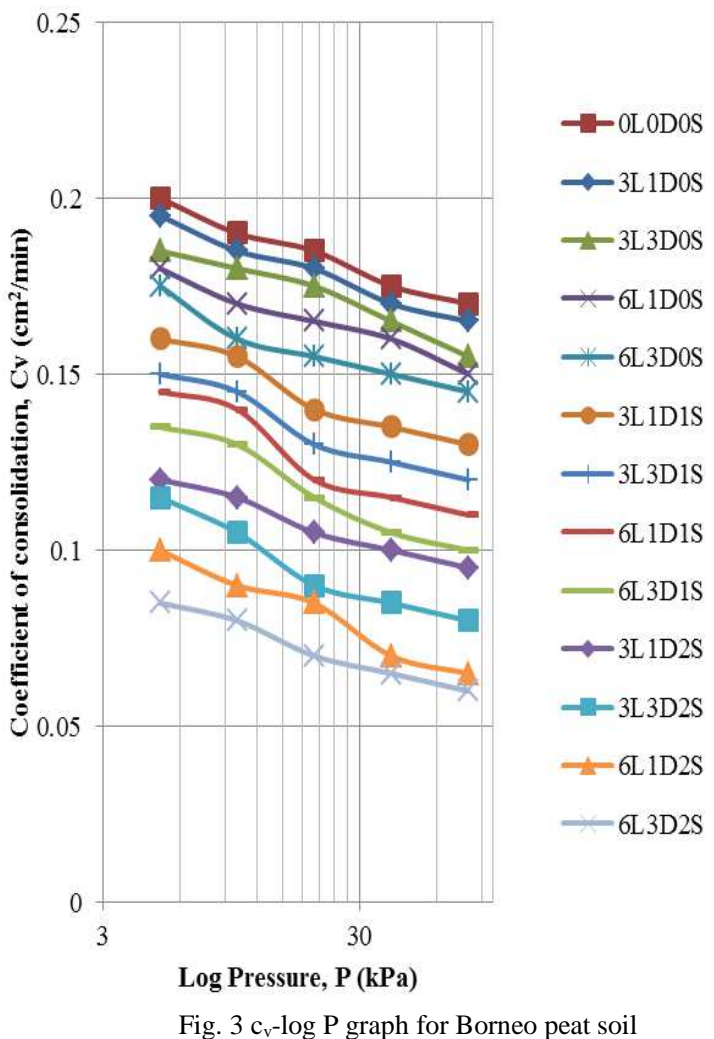

A number of sand columns also affects the $c_{v}$ of the peat soil. The samples treated with $3 \%$ lime cured for 1 day with 1 sand column and 2 sand column showed a $c_{v}$ value of 0.16 and $0.12 \mathrm{~cm}^{2} / \mathrm{min}$ respectively. The $\mathrm{c}_{\mathrm{v}}$ appeared to be reduced by the increasing number of sand column. Addition of pressure causes greater compaction between the soil particles, making it denser by reducing the void ratio of the soil. The rearrangement of the soil particles into denser state causes the compressibility of the peat soil to reduce and cause a large reduction in permeability [18].

The general trend among all the peat soil sample is increasing the value of the coefficient of volume compressibility, $\mathrm{m}_{\mathrm{v}}$ at $10 \mathrm{kPa}$ and started to decrease with the addition of subsequent pressures as shown in Fig. 4. Using the final point of $\mathrm{m}_{\mathrm{v}}$ which is at $80 \mathrm{kPa}$ as the reference point for comparison, the $\mathrm{m}_{\mathrm{v}}$ of the untreated peat soil shows the highest value, which is $17.96 \times 10^{-4} \mathrm{~m}^{2} / \mathrm{kN}$. The lime-treated peat shows a reduction in $\mathrm{m}_{\mathrm{v}}$, where sample treated with 3 and $6 \%$ lime, both cured for 1 day shows $m_{v}$ value of $16.84 \times 10^{-4}$ and $14.94 \times 10^{-4} \mathrm{~m}^{2} / \mathrm{kN}$ respectively. Meanwhile, prolong curing time was found to reduce the compressibility of peat soil. For example, peat soil treated with $3 \%$ lime cured for 1 day and 3 days show the value of $18.84 \times 10^{-4}$ and $15.52 \times 10^{-4} \mathrm{~m}^{2} / \mathrm{kN}$ respectively. Addition of sand column also has effect in reducing the compressibility of the soil. Peat treated with $6 \%$ lime cured for 1 day with 1 sand column and 2 sand columns each showed the value of $11.12 \times 10^{-4}$ and $8.94 \times 10^{-4} \mathrm{~m}^{2} / \mathrm{kN}$ respectively.

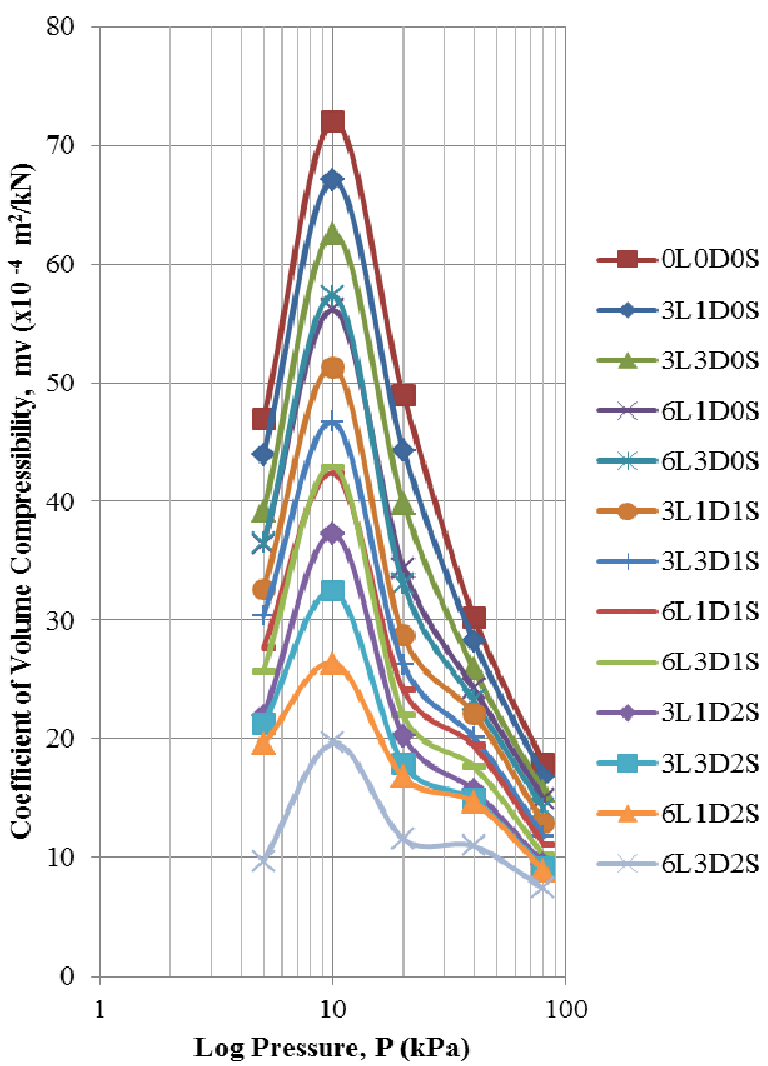

Fig. $4 \mathrm{~m}_{\mathrm{v}}-\log \mathrm{P}$ graph for Borneo peat soil

However, the $m_{v}$ value at the pressure of $10 \mathrm{kPa}$ for the peat treated with $6 \%$ lime cured for 1 day is lower than the sample treated with $6 \%$ lime cured for 3 days, which is $56.14 \times 10^{-4}$ compared to $57.32 \times 10^{-4} \mathrm{~m}^{2} / \mathrm{kN}$. The same abnormally can also be observed between the samples treated with $6 \%$ lime added with 1 sand column cured for 1 and 3 days. Edil [7] suggested that peat soil is more prone to decomposition during odeometer testing and that the additional gas generation may complicate the interpretation of oedometer tests.

The shape of the coefficient of compressibility, $a_{v}$ versus $\log$ pressure graph is the same as the $\mathrm{m}_{\mathrm{v}}$ versus log pressure graph as shown in Fig. 5. The $\mathrm{a}_{\mathrm{v}}$ value of untreated peat soil at $80 \mathrm{kPa}$ is $0.0155 \mathrm{~m}^{2} / \mathrm{kN}$. Addition of lime into the sample reduces the coefficient of compressibility of soil, where peat soil treated with 3 and $6 \%$ lime, both cured for 1 day each show a value of 0.0145 and $0.0125 \mathrm{~m}^{2} / \mathrm{kN}$ respectively. Longer curing period decreases the coefficient of compressibility. The fact is shown by $\mathrm{a}_{\mathrm{v}}$ of the soil which is 0.0145 and $0.0133 \mathrm{~m}^{2} / \mathrm{kN}$ respectively for peat treated with $3 \%$ lime cured for 1 and 3 days. 


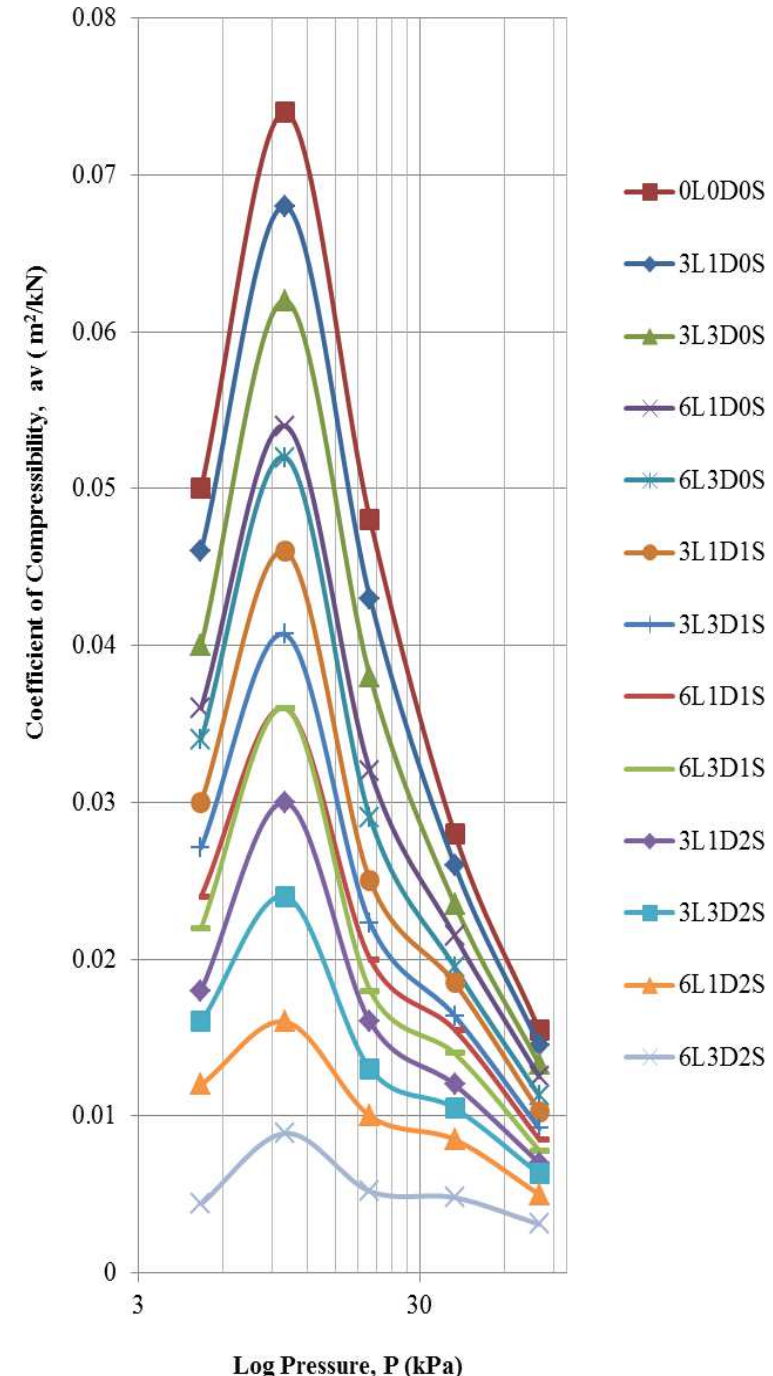

Fig.5 $\mathrm{a}_{\mathrm{v}}-\log \mathrm{P}$ graph for Borneo peat soil

The higher amount of sand column reduces the $a_{v}$ of the peat soil where peat treated with $3 \%$ lime cured for 1 day added with 1 and 2 sand columns shows the value of 0.0103 and $0.0070 \mathrm{~m}^{2} / \mathrm{kN}$ respectively.

\section{CONCLUSIONS}

Generally, incorporation of the lime-sand column reduces the compressibility of Borneo peat soil as observed from the void ratio, coefficient of consolidation, coefficient of compressibility and the coefficient of volume compressibility. The reduction in e, $\mathrm{c}_{\mathrm{v}}, \mathrm{a}_{\mathrm{v}}$, and $\mathrm{m}_{\mathrm{v}}$ is caused by the increasing density of the soil and decreasing water content as the soil undergoes the process of consolidation and stabilization. Lime acts as a binder between the soil particles and is responsible for accelerating the reduction of compressibility.

Longer curing time decreases the soil compressibility as it achieves a greater reduction in initial void ratio. Longer curing period produces more reaction that binding the soil particles by allowing more time frames for the stabilization process to take place. Huat [5] noted that the chemical reaction between additives and soil are time-dependent.
During the third day, chemical reactions still occurred in the peat soil, as indicated by all the graphs.

A higher number of sand columns decreases the compressibility of peat soil as the amount of the reaction is higher. Wong [19] suggested that stabilized peat become denser with the increase of silica sand in addition to the formation of more calcium silicate hydrates which is the major cementing products in the stabilized soil with a higher dosage of binder and prolonged curing time in the water.

Lime is known to react with silica in the sand. As cementation effect in silica sand takes place in the form of cementation products, they bind the organic particles together [20]. Therefore, the organic particles in peat not only fill up the void spaces but also tied up [21]. In physical terms, the particle shape of the sand is almost spherical and uniform, and the structure of each grain is strong and sound with almost no interval voids. These allow the sand to be exposed to more contact points with the lime [22]. In addition, the sand column provides drainage for the seepage of water from the peat soil. The presence of sands acts as a good drainage material, which alternatively helps in good seepage of lime into the soil system effectively.

\section{ACKNOWLEDGMENT}

The authors would like to thank the Universiti Malaysia Sabah (UMS), Malaysia for providing the facilities and financial aids in completing this research.

\section{REFERENCES}

[1] M.R.C. Posa, L.S. Wijedasa and R.T. Corlett, "Biodiversity and conservation of tropical peat swamp forests", BioScience, volume 61 (1), pp 49-57, Jan 2011.

[2] (2017) The Star website. [Online]. Available: http://www.thestar.com.my/news/nation/2014/12/02/peat -soil-challenge-for-pan-borneo-highway-builders/

[3] B.K. Huat, "Problematic Soils: In Search for Solution", Inaugural Lecture, $1^{\text {st }}$ Edition, Universiti Putra Malaysia Press. 2010

[4] F. Tongkul, "Natural Disaster and Sustainable Environment in Malaysia: Issues and Challenges" in Proc. of the Seminar on Science and Technology, Universiti Malaysia Sabah, 2008, p.1.

[5] B.K. Huat, Organic and Peat Soils Engineering, 1st ed., University Putra Malaysia Press, 2004.

[6] M. S. Islam, and R. Hashim, "Use of Mackintosh probe test for field investigation in peat soil". Proc. of Int. Conference on Highway and Geotechnical Engineering, Kuala Lumpur Malaysia, 2008, p. 27.

[7] T. B. Edil, "Recent advances in geotechnical characterization and construction over peats and organic soils," Proc. of the $2^{\text {nd }}$ International Conferences in Soft Soil Engineering and TechnologyPutrajaya, 2003., p. 3-26.

[8] C.M. Yule, "Loss of biodiversity and ecosystem functioning in IndoMalayan peat swamp forests", Biodiversity and Conservation, volume 19, p. 393-409. Feb 2010.

[9] H. Ahnberg, "Consolidation stress effects on the strength of stabilised swedish soils. Ground Improvement", Proc. of the Institution of Civil Engineers - Ground Improvement, 2006, p. 1-13.

[10] S.Widodo1, S.Hong, A. Ibrahim., "Influence of repeated loading and geosynthetic reinforcement on base course thickness over soft soil", International Journal on Advanced Science Engineering and Information Technology, volume 2, No 2, pp. 5-9, 2012.

[11] M.I. Zaini , Kasa A. and Mohd Nayan K.A, "Interface shear strength of geosynthetic clay liner (GCL) and residual soil", International Journal on Advanced Science Engineering and Information Technology, volume 2, No 2, pp . 43-45, 2012.

[12] S. Hebib and R.E. Farell, "Some experiences on the stabilization of Irish peats", Canadian Geotechnical Journal, volume 40 (1), pp. 107-120, Feb 2003. 
[13] Z. Adnan and M. M. Habib, "Engineering properties of integrated tropical peat soil in Malaysia", Electronic Journal of Geotechnical Engineering, volume 22, bundle 02, 2017.

[14] M. R. Aminur, P. K. Kolay, S. N. L. Taib, M. I. S. Mohd Zain and A. A. Kamal, "Physical, geotechnical and morphological characteristics of peat soils from Sarawak". Journal of The Institution of Engineers, Malaysia, volume 72, no. 4, pp. 12-16, April 2011.

[15] S. N. A. Zolkefle "The dynamic characteristic of Southwest Johor peat under different frequencies". M. Eng. thesis, Universiti Teknologi Malaysia, Johor, Malaysia, 2014.

[16] M. M. Habib and Z Adnan, "Pre- and post-cyclic behavior on monotonic shear strength of Penor peat". Electronic Journal of Geotechnical Engineering, volume 20, bundle 15, 2015.

[17] G. Nurly, "Study of compressibility characteristics of peat soil using large strain consolidometer", Proc. Of SEPKA, Johor Bahru, 2005. p. 119-129,
[18] M. Ajlouni, "Geotechnical properties of peat and related engineering problems". PhD Dissertation, University of Illinois at UrbanaChampaign, 2000.

[19] L. S. Wong, Hashim, R. and Ali F. H., "Compression rates of untreated and stabilized peat soils", Electronic Journal of Geotechnical Engineering, volume 13, bundle F, pp 1-13, 2009.

[20] R, S. Narasimha and G. Rajasekaran, "Reaction products formed in lime-stabilized marine clays". Journal of Geotechnical Engineering, volume 122, pp. 329-336, 1996.

[21] A. Kezdi, Stabilized Earth Roads. $1^{\text {st }}$ Edition. New York Elsevier Scientific Publishing Company, 1979.

[22] M. A. Ismail,, H.A. Joer, M.F. Randolph and A. Meritt, "Cementation of porous materials using calcite". Geotechnique. Volume 52 (5), pp 313-324, 2002. 